\title{
Photochemistry of Squaraine Dyes: Excited Triplet State and Redox Properties of Crown Ether Squaraines
}

\author{
Genevieve Sauve and Prashant V. Kamat ${ }^{*}, \dagger$ \\ Radiation Laboratory, University of Notre Dame, Notre Dame, Indiana 46556 \\ K. George Thomas, K. J. Thomas, Suresh Das,* and M. V. George*,* \\ Photochemistry Research Unit, Regional Research Laboratory (CSIR), Trivandrum 695 019, India
}

Received: July 24, 1995; In Final Form: October 17, $1995^{\circledR}$

\begin{abstract}
The excited state and redox properties of three crown-ether derivatives of squaraines have been studied. Direct laser excitation of these dyes leads to the formation of excited triplets, dye radical cations and anions, via a biphotonic photoionization mechanism. All these transient species absorb strongly in the visible region. The triplet states of these dyes generated via triplet-triplet energy transfer from ${ }^{3}$ (1-pyrenecarboxaldehyde)* and ${ }^{3} \mathrm{C}_{60} *$ photosensitizers also produce dye radical cations and anions via a self-quenching process. The bimolecular rate constants for the self-quenching process are in the range of $(0.5-1.9) \times 10^{9} \mathrm{M}^{-1} \mathrm{~s}^{-1}$. The redox properties of these dyes have been investigated by electrochemical, spectroelectrochemical, and radiolytic methods. They exhibit two reversible oxidations in the potential range of $0.7-1.2 \mathrm{~V}$ vs SCE. The spectral features of electrochemically generated one electron oxidation product $\left(\lambda_{\max }=680 \mathrm{~nm}\right)$ match those of dye radical cations produced by photochemical and radiolytic methods.
\end{abstract}

\section{Introduction}

Squaraine dyes have important applications in imaging science and in the sensitization of wide band gap semiconductor materials. The symmetric $\mathrm{D}-\mathrm{A}-\mathrm{D}$ (donor-acceptor-donor) arrangement of symmetrical squaraine dyes causes an interesting effect on the formation of intramolecular charge transfer states. $^{1-3}$ As a result, the photophysical properties of these dyes are highly sensitive to substituent groups and the solvent medium., ${ }^{4,5}$ For example, the fluorescence yield of a hydroxy derivative of a squaraine dye can be greatly enhanced by microencaging within a polymer matrix ${ }^{6}$ or $\beta$-cyclodextrin. ${ }^{7}$ Microencapsulation of these dyes restricts the rotation about the $\mathrm{C}-\mathrm{C}$ bond between the central $\mathrm{C}_{2} \mathrm{O}_{4}$ unit and its neighbor in the excited state. There have been efforts to adsorb squaraine dyes on nanocrystalline semiconductor films and incorporate them in polymers ${ }^{8,9}$ and Langmuir-Blodgett films. ${ }^{10}$ These dyes have been shown to sensitize large band gap semiconductors and extend their photoresponse into the visible. ${ }^{1-15}$ Recently, Law has investigated the photophysical properties of several unsymmetrical squaraines. ${ }^{16}$

We have synthesized a new class of squaraine dyes that contain an ionophoric moiety. ${ }^{17,18}$ Ionophores that are covalently linked to chromophores exhibit intramolecular charge transfer (ICT) transitions. ${ }^{19-21}$ Excitation of such molecules causes a redistribution of their charge densities, which can significantly affect the metal ion binding ability of the ionophoric unit. $^{22,23}$ Alternatively, the ICT transition can be severely affected by complexation with metal ions, leading to significant changes in the absorption and emission properties of these molecules. ${ }^{17}$ Such molecules can therefore be utilized for the selective and quantitative detection of biologically important metal ions such as $\mathrm{Li}^{+}, \mathrm{Na}^{+}, \mathrm{K}^{+}$, and $\mathrm{Ca}^{2+}$. For intracellular applications it is desirable to design fluoro- or chromoionophores that are water soluble and absorb strongly in the near infrared

$\dagger$ E-mail address: Kamat.1@nd.edu.

$¥$ Also at the Notre Dame Radiation Laboratory.

${ }^{\otimes}$ Abstract published in Advance ACS Abstracts, January 1, 1996. region. Additionally, if the chromophoric unit is redox active, such molecules can be utilized for transportation of ions across membranes as well as in the design of ion sensitive electrodes. ${ }^{18}$

We have recently reported on the synthesis, photophysics, and metal ion binding properties of several crown ether derivatives of squaraine dyes. ${ }^{17}$ By employing picosecond laser flash photolysis, we were able to characterize the singlet excited state of these dyes. ${ }^{17 \mathrm{~b}}$ Since the intersystem crossing efficiency of these squaraines was very low, the triplet formation was not observed with direct excitation. Here, we report a detailed study of the triplet excited state properties and reduced and oxidized forms of three crown ether squaraines (Chart 1). The triplets were generated via triplet-triplet energy transfer using 1-pyrenecarboxaldehyde and $\mathrm{C}_{60}$ as photosensitizers. The dye radical cations were characterized by electrochemical and pulse radiolytic methods.

\section{Experimental Section}

Materials and Methods. The synthesis of crown ether derivatives of squaraine dyes $\mathbf{1 , 2}$, and $\mathbf{3}$ is described in an earlier publication. ${ }^{17 \mathrm{~b}}$ All samples were obtained by diluting concentrated stock solutions $\left(\sim 1 \mathrm{mM}\right.$ dye in chloroform, $1 \mathrm{mM} \mathrm{C}_{60}$ (SES Research) in toluene, $1 \mathrm{mM}$ 1-pyrenecarboxaldehyde (Aldrich) in acetonitrile, and $10 \mathrm{mM}$ triphenylamine (Aldrich) in acetonitrile) to obtain the desired final concentrations. Unless otherwise specified, all solutions were deaerated with nitrogen or argon prior to the experiments. All the experiments were performed at room temperature $(\sim 300 \mathrm{~K})$.

Laser Flash Photolysis. Direct excitation of the squaraine dye solution was carried out using the second harmonic of a Quanta-Ray CDR-1 Nd:YAG pulsed laser (532 nm, $6 \mathrm{~ns}$ pulse width, $10-50 \mathrm{~mJ} /$ pulse). The third harmonic of the same laser (355 nm, $10 \mathrm{~mJ} /$ pulse) was used for $\mathrm{T}-\mathrm{T}$ sensitization and electron transfer reaction of squaraine triplets with triphenylamine. For the triplet-triplet energy transfer studies the Molectron UV-400 nitrogen laser system (337.1 nm, $8 \mathrm{~ns}$ pulse, $1 \mathrm{~mJ} /$ pulse) was also used. 


\section{CHART 1}
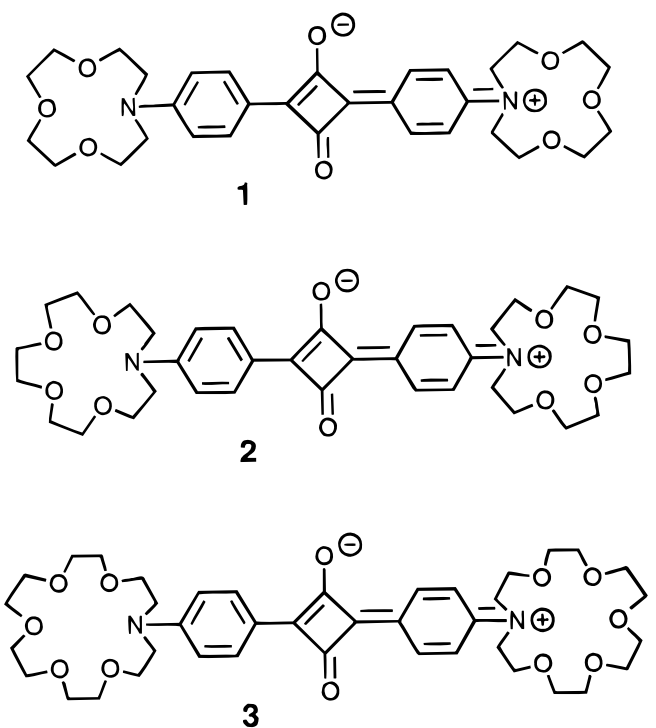

The experiments were performed in a rectangular quartz cell of $6 \mathrm{~mm}$ path length with a right angle configuration between the direction of laser excitation and analyzing light. A typical experiment consisted of 4-6 replicate shots per single measurement. The average signal was processed with an LSI-11 microprocessor interfaced to a VAX computer. Details of the experimental setup are described elsewhere. ${ }^{24}$

Electrochemical and Spectroelectrochemical Measurements. These measurements were carried out in a thin layer cell consisting of a 2 or $5 \mathrm{~mm}$ path length quartz cuvette with two side arms attached for inserting reference ( $\mathrm{Ag} / \mathrm{AgCl}$ or SCE) and counter ( $\mathrm{Pt}$ gauze) electrodes. The description of the cell can be found elsewhere. ${ }^{25}$ A Princeton Applied Research (PAR) Model 173 potentiostat and Model 175 universal programmer and BAS Model 100 electrochemical analyzer were used in electrochemical and spectroelectrochemical measurements. Absorption and emission measurements were made using a PerkinElmer 3840 diode array spectrophotometer and SLM 8000C fluorometer, respectively.

Pulse Radiolysis. These experiments were performed at 296 $\mathrm{K}$ with the Notre Dame $7 \mathrm{MeV}$ ARCO LP-7 linear accelerator, the operating conditions of which are described elsewhere. ${ }^{26}$ The dose per pulse was in the range of 1-5 Gy, determined by thiocyanate dosimetry. The solutions were saturated with nitrogen or oxygen and flowed continuously during the experiment.

\section{Results and Discussion}

Direct Excitation with 532 nm Laser Pulse. The crownether-linked squaraine dyes $\mathbf{1 - 3}$ (Chart 1) have very strong absorption bands centered around $630 \mathrm{~nm}\left(\epsilon_{634 \mathrm{~nm}}=3 \times 10^{5}\right.$ $\mathrm{M}^{-1} \mathrm{~cm}^{-1}$ in $\mathrm{CHCl}_{3}$ ). Although the extinction coefficient of this band is substantially smaller at $532 \mathrm{~nm}\left(\epsilon_{532 \mathrm{~nm}}=1.4 \times\right.$ $10^{3} \mathrm{M}^{-1} \mathrm{~cm}^{-1}$ in $\mathrm{CHCl}_{3}$ ), direct excitation by the second harmonic of the $\mathrm{Nd}$ :YAG laser is possible. It has been shown earlier ${ }^{17 \mathrm{~b}}$ that relatively high fluorescence yields can be observed in nonpolar solvents $\left(\Phi_{\mathrm{f}}=0.78\right.$ in benzene). On the other hand, the fluorescence yields were low in polar solvents $\left(\Phi_{\mathrm{f}}=0.13\right.$ in acetonitrile). The singlet excited state properties were characterized by picosecond laser flash photolysis using 532 $\mathrm{nm}$ laser pulses of $18 \mathrm{ps}$ pulse width. Typically, the excited singlet states of these molecules have an absorption band in the $480 \mathrm{~nm}$ region and possess lifetimes of about $2-3 \mathrm{~ns}$ in benzene and $\sim 100$ ps in water. ${ }^{17 b}$

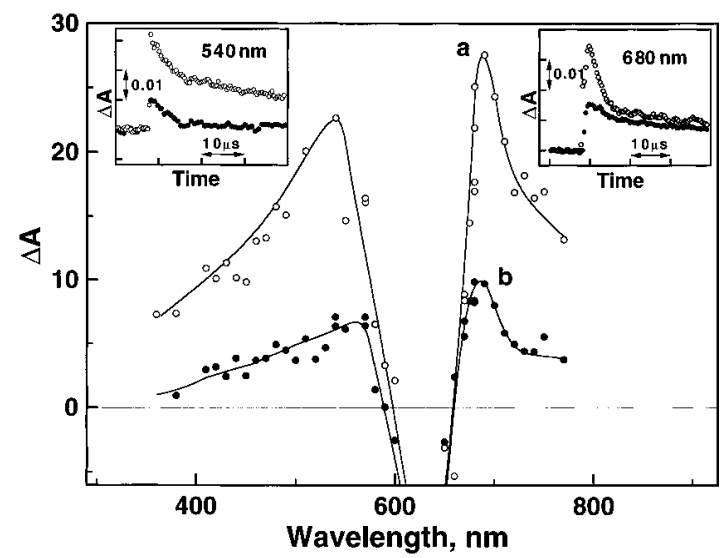

Figure 1. Transient absorption spectra obtained (a) 1.2 and (b) $22 \mu \mathrm{s}$ after $532 \mathrm{~nm}$ laser pulse excitation of $1(20 \mu \mathrm{M})$ in deaerated acetonitrile. Inset shows the absorption-time profile at 540 and $680 \mathrm{~nm}$ of $\mathrm{N}_{2}$-saturated $(\mathrm{O})$ and air-saturated $(\bullet)$ dye solutions.

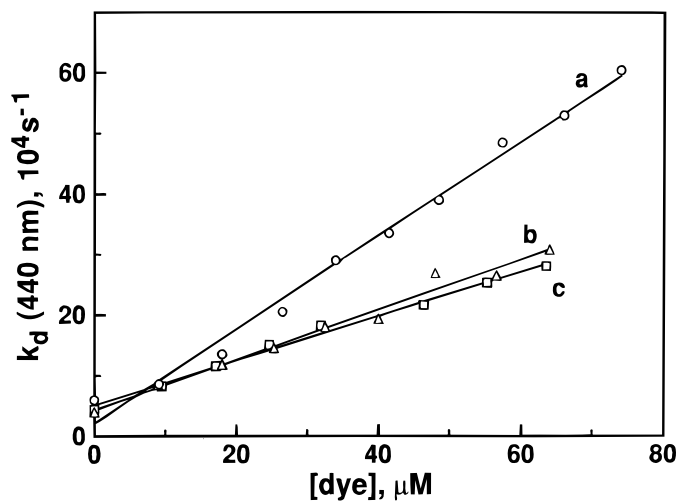

Figure 2. Quenching of ${ }^{3}(1-$ pyrenecarboxaldehyde $) *$ by squaraine dyes (a) 1, (b) 2 , and (c) 3 in acetonitrile. The pseudo-first-order rate constant of ${ }^{3}(1$-pyrenecarboxaldehyde)* was monitored at $440 \mathrm{~nm}$. The concentration of 1-pyrenecarboxaldehyde was $10 \mu \mathrm{M}$ (excitation, $337 \mathrm{~nm}$ ).

The transient absorption spectra obtained by the nanosecond laser flash photolysis of $\mathbf{1}$ in deaerated acetonitrile solution are shown in Figure 1. A bleaching at $630 \mathrm{~nm}$ and transient absorption maxima at 540 and $680 \mathrm{~nm}$ are observed. The transient absorption at $540 \mathrm{~nm}$ is prompt and is quenched readily by dissolved oxygen (see inset of Figure 1). We attribute this absorption band to triplet excited dye.

The transient absorption at $680 \mathrm{~nm}$, however, consists of species other than the triplet excited dye. Even in air-saturated solutions, a significant amount of transient absorption is observed (see inset in Figure 1). It is proposed that the transient absorption at $680 \mathrm{~nm}$ is due to the cation and anion radicals of the dye (reactions 1 and 2).

$$
\begin{gathered}
\text { dye } \stackrel{h v}{\longrightarrow} \text { dye }^{*} \stackrel{h v}{\longrightarrow} \mathrm{dye}^{\bullet+}+\mathrm{e}_{\mathrm{sol}} \\
\text { dye }+\mathrm{e}_{\mathrm{sol}} \rightarrow \mathrm{dye}^{\cdot-}
\end{gathered}
$$

Since both $\mathrm{S}_{0}$ and $\mathrm{S}_{1}$ states exhibit significant absorption at the excitation wavelength $(532 \mathrm{~nm})$, multiphotonic excitation of the dye is possible within the duration of the laser pulse. These effects are more evident at high laser intensities as the dye molecules photoionize. Similar biphotonic photoionization has also been observed for bis(4-(dimethylamino)phenyl)squaraine. ${ }^{3}$ Photoionization of $\mathbf{1}$ yields dye radical cations and solvated electrons (reaction 1). The reaction of these solvated electrons with the ground state dye molecules produces dye radical anions (reaction 2). Because of the fast recombination reaction between the cation and anion radicals and the overlap 
TABLE 1: Excited Triplet Characteristics

\begin{tabular}{|c|c|c|c|c|c|c|c|c|}
\hline \multirow[b]{2}{*}{ dye } & \multicolumn{4}{|c|}{ 1-pyrenecarboxaldehyde as sensitizer in acetonitrile } & \multicolumn{4}{|c|}{$\mathrm{C}_{60}$ as sensitizer in chloroform } \\
\hline & $\lambda_{\max }(\mathrm{nm})$ & $\Delta \epsilon_{\max }^{a}\left(10^{4} \mathrm{M}^{-1} \mathrm{~cm}^{-1}\right)$ & lifetime $^{b}(\mu \mathrm{s})$ & $k_{\mathrm{q}}^{c}\left(10^{9} \mathrm{M}^{-1} \mathrm{~s}^{-1}\right)$ & $\lambda_{\max }(\mathrm{nm})$ & $\Delta \epsilon_{\max }{ }^{d}\left(10^{4} \mathrm{M}^{-1} \mathrm{~cm}^{-1}\right)$ & lifetime $^{b}(\mu \mathrm{s})$ & $k_{\mathrm{q}}^{c}\left(10^{9} \mathrm{M}^{-1} \mathrm{~s}^{-1}\right)$ \\
\hline 1 & 560 & 0.7 & 53 & 0.3 & 570 & $5.3=$ & 32 & 0.05 \\
\hline 2 & 560 & $8.5 \pm 0.4$ & 94 & $4.0 \pm 0.2$ & 570 & 6.4 & 67 & $3.7 \pm 0.2$ \\
\hline 3 & 560 & $7.1 \pm 0.6$ & 50 & $3.7 \pm 0.1$ & 570 & $4.9 \pm 0.4$ & 91 & $3.1 \pm 0.2$ \\
\hline
\end{tabular}

${ }^{a}$ By employing T-T energy transfer method; $\epsilon_{440}$ for ${ }^{3}\left(1\right.$-pyrenecarboxaldehyde) $*=18400 \mathrm{M}^{-1} \mathrm{~cm}^{-1} .{ }^{27}{ }^{b}$ Life time obtained by extrapolation of the self-quenching plot to [dye] $=0 \mathrm{M}$ or longest recorded. ${ }^{c}$ Bimolecular quenching rate constant for energy transfer between sensitizer and squaraine dye, calculated as the slope of the graph of rate constant of decay at maximum absorbance of sensitizer versus dye concentration. ${ }^{d} \mathrm{By}$ employing T-T energy transfer method; $\epsilon_{740}$ for ${ }^{3} \mathrm{C}_{60} *=16000 \mathrm{M}^{-1} \mathrm{~cm}^{-1} .31,32$
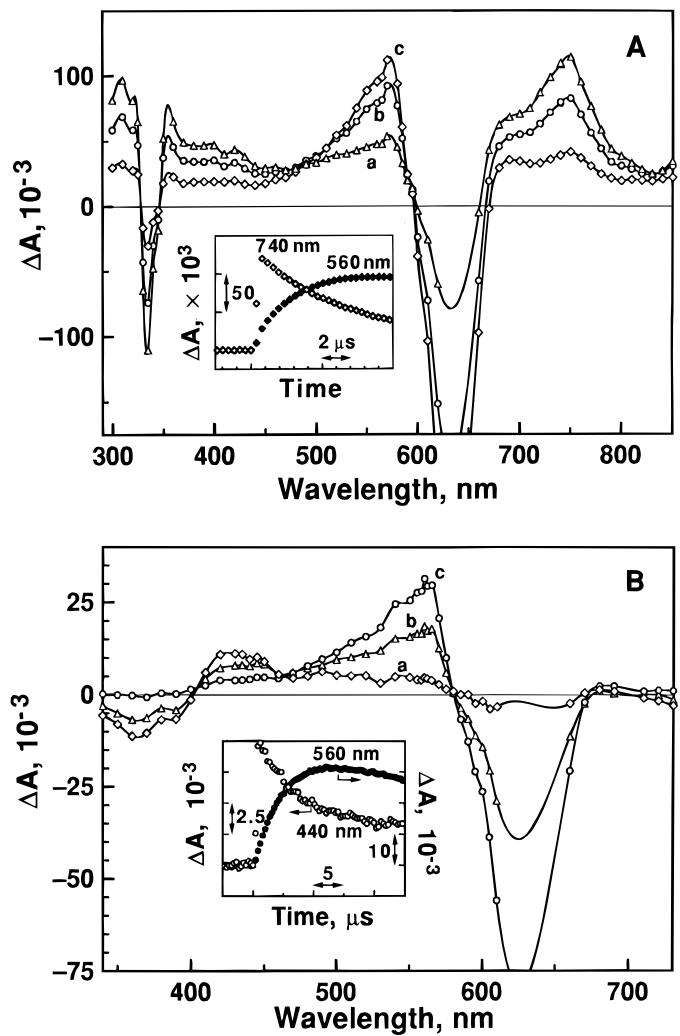

Figure 3. (A) $\mathrm{T}-\mathrm{T}$ energy transfer between ${ }^{3} \mathrm{C}_{60} *$ and $\mathbf{1}(20 \mu \mathrm{M})$ in chloroform. The transient absorption spectra were recorded at (a) 1.6 , (b) 4.0 , and (c) $9.8 \mu \mathrm{s}$ after the $337 \mathrm{~nm}$ laser pulse excitation. The absorbance-time profiles in the inset show the decay of ${ }^{3} \mathrm{C}_{60} *$ at 740 $\mathrm{nm}$ and formation of ${ }^{3} \mathbf{1}^{*}$ at $560 \mathrm{~nm}$. The concentration of $\mathrm{C}_{60}$ was 20 $\mu \mathrm{M}$. (B) Energy transfer between ${ }^{3}$ (1-pyrenecarboxaldehyde)* and 2 $(20 \mu \mathrm{M})$ in acetonitrile. The transient absorption spectra were obtained (a) 0.8 , (b) 3.5 , and (c) $13.7 \mu \mathrm{s}$ after the $337 \mathrm{~nm}$ laser pulse excitation. The absorption-time profiles in the insets show the decay of the sensitizer triplet at $440 \mathrm{~nm}$ and the formation of ${ }^{3} 2 *$ at $560 \mathrm{~nm}$. The concentration of 1-pyrenecarboxaldehyde was $10 \mu \mathrm{M}$.

of their absorption at $680 \mathrm{~nm}$, it is not possible to observe a clean growth of the dye radical anion. In air-saturated solutions the anion radical formation is supressed as dissolved oxygen scavenges away the solvated electron.

These results suggest that radical cation and radical anion of the squaraine dye, $\mathbf{1}$, absorb in the same region $(\sim 680 \mathrm{~nm})$ with the radical anions having a lower extinction coefficient than the radical cation. Thus, excited triplet, radical anion, and radical cation are the major reaction intermediates that result from direct excitation of the dye. In order to resolve these spectral components, different experimental approaches were employed so that only one of these intermediates is selectively generated in each set of experiment.

Excited Triplet State via $\mathbf{T}-\mathbf{T}$ Sensitization. The triplettriplet energy transfer process is an excellent method to characterize the triplet excited state of a given molecule. Photosensitizers such as 1-pyrenecarboxaldehyde $\left(E_{\mathrm{T}}=186 \mathrm{~kJ}\right.$
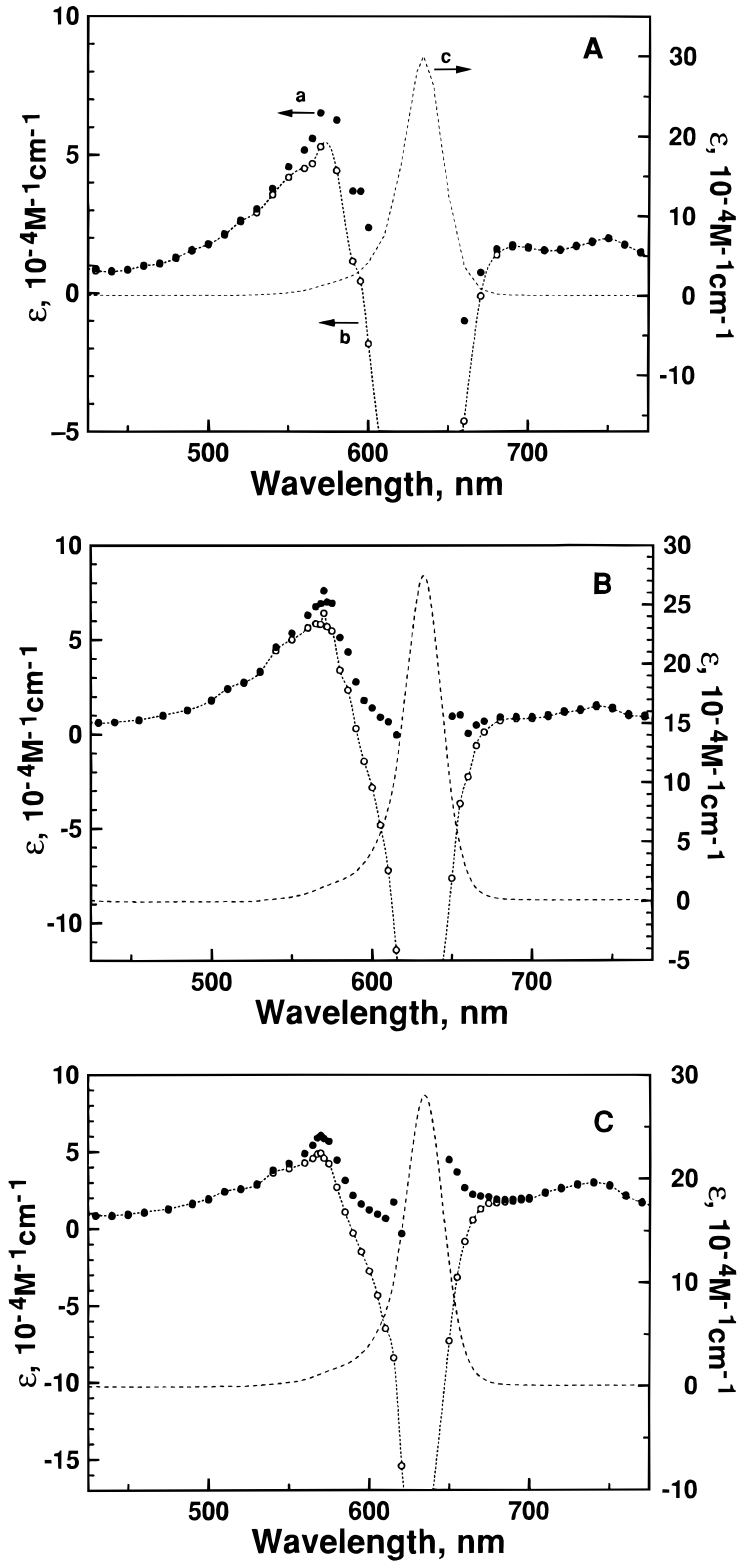

Figure 4. Comparison of the absorption spectra of ground state and triplet excited dye molecules, (A) 1, (B) 2, and (C) 3: (a) ground state absorption spectra of dye, (- - ) (b) difference absorption spectra of ${ }^{3}(\mathrm{dye})^{*}(\mathrm{O})$, and (c) corrected triplet-triplet absorption spectra $(\bullet)$. The difference absorption spectra were recorded at 9.8, 16.0, and 12.5 $\mu$ s after the $337 \mathrm{~nm}$ laser pulse excitation for $\mathbf{1 - 3}$, respectively. In all cases $20 \mu \mathrm{M} \mathrm{C}_{60}$ was used as the triplet sensitizer.

$\left.\mathrm{mol}^{-1}\right)^{27}$ and $\mathrm{C}_{60}\left(E_{\mathrm{T}}=151 \mathrm{~kJ} \mathrm{~mol}^{-1}\right)^{28,29}$ were able to generate detectable amounts of dye triplets according to eq 3 .

$$
{ }^{3}(\text { Sens })^{*}+\text { dye } \rightarrow \text { Sens }+{ }^{3}(\text { dye })^{*}
$$

The bimolecular rate constants for the quenching of ${ }^{3}$ (Sens)* were determined by monitoring the pseudo-first-order decay rate constants of ${ }^{3}(\mathrm{Sens}) *$ at various dye concentrations. Figure 2 


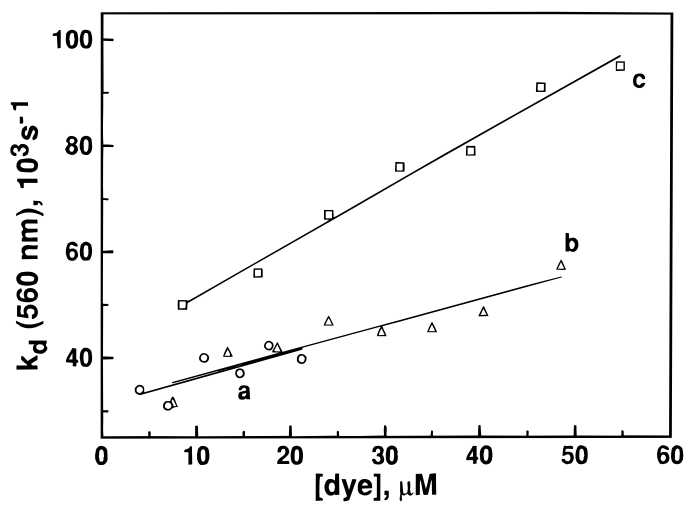

Figure 5. Quenching of the squaraine dye triplets (monitored at 560 $\mathrm{nm}$ ) with ground state molecules in chloroform: (a) 1, (b) 2, and (c) 3. $\mathrm{C}_{60}(20 \mu \mathrm{M})$ was used as the sensitizer.
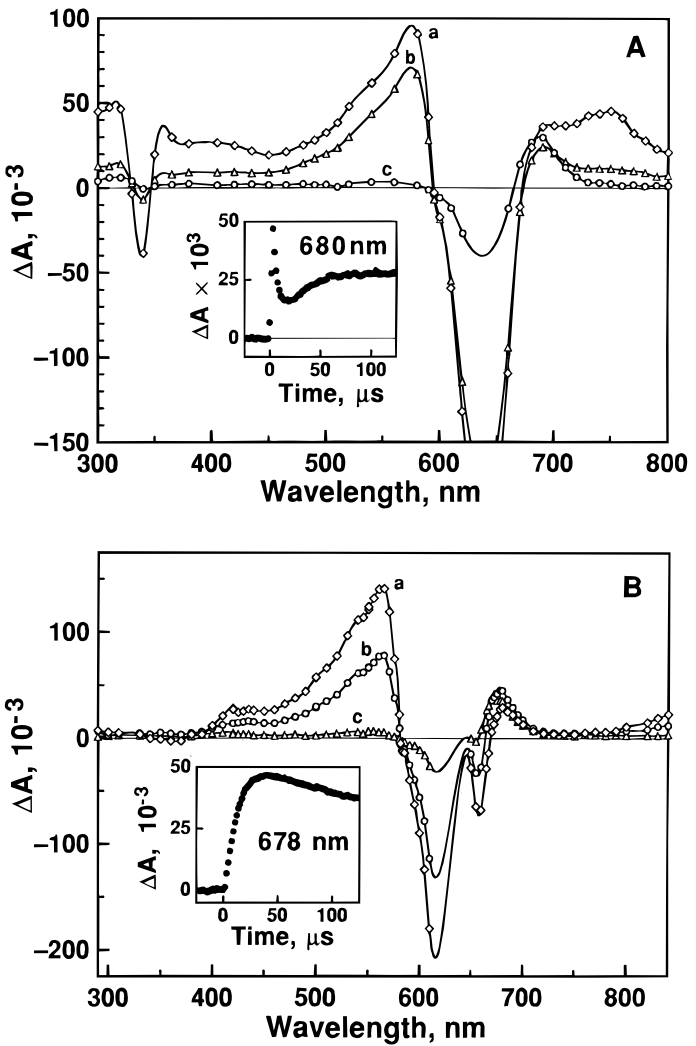

Figure 6. Transient spectra showing the electron transfer products in the ground state quenching process. (Note the formation of absorption peak at $680 \mathrm{~nm}$.) The absorption-time profiles in the insets show the formation of the electron transfer products. (A) $\mathbf{1}(20 \mu \mathrm{M}), \mathrm{C}_{60}(20$ $\mu \mathrm{M}$ ), in $\mathrm{CHCl}_{3}$; recorded at (a) 7.8, (b) 20.3, and (c) $70.3 \mu$ s after 337 nm laser pulse excitation. (B) $1(20 \mu \mathrm{M}), 1$-pyrenecarboxaldehyde $(10$ $\mu \mathrm{M}$ ), in ACN; recorded at (a) 10.9, (b) 31.3, and (c) $129.7 \mu$ s after the $337 \mathrm{~nm}$ laser pulse excitation.

TABLE 2: Bimolecular Rate Constants ${ }^{a}$ for the Self-Quenching Reactions of Squaraine Dye Triplets in ACN and $\mathrm{CHCl}_{3}$

\begin{tabular}{ccc}
\hline dye & $\begin{array}{c}k_{\mathrm{sq}}\left(10^{9} \mathrm{M}^{-1} \mathrm{~s}^{-1}\right) \\
\text { in ACN }\end{array}$ & $\begin{array}{c}k_{\mathrm{sq}}\left(10^{9} \mathrm{M}^{-1} \mathrm{~s}^{-1}\right) \\
\text { in } \mathrm{CHCl}_{3}\end{array}$ \\
\hline $\mathbf{1}$ & $1.9 \pm 0.1$ & $0.5 \pm 0.2$ \\
$\mathbf{2}$ & $0.93 \pm 0.06$ & $0.48 \pm 0.08$ \\
$\mathbf{3}$ & $0.63 \pm 0.03$ & $1.01 \pm 0.05$
\end{tabular}

${ }^{a}$ The rate constants were obtained from the slope of the linear plot of the decay rate constant of triplet versus ground state dye concentration.

shows the linear dependence of the pseudo-first-order rate of decay of triplet excited 1-pyrenecarboxaldehyde (monitored at $440 \mathrm{~nm}$ ) on the dye concentration. The quenching rate constants

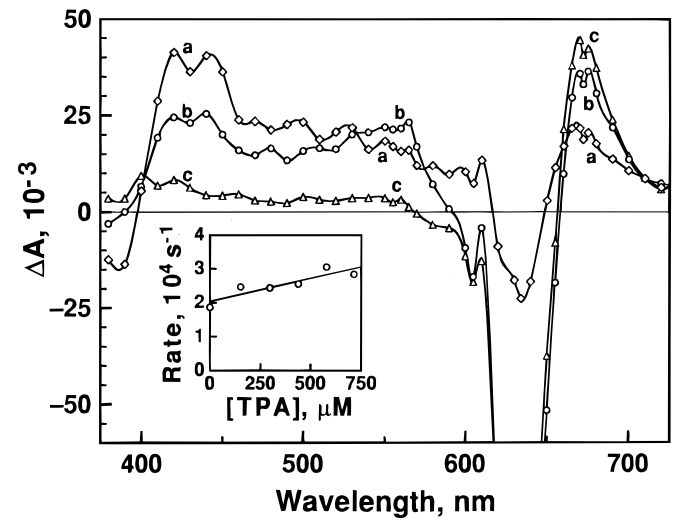

Figure 7. Transient absorption spectra obtained after $355 \mathrm{~nm}$ laser pulse excitation of $\mathbf{1}(10 \mu \mathrm{M})$ in acetonitrile with 1-pyrenecarboxaldehyde $(10 \mu \mathrm{M})$ and triphenylamine $(0.7 \mathrm{mM})$. The spectra were recorded at (a) 0.8 , (b) 7.2 , and (c) $56 \mu \mathrm{s}$ after the laser pulse excitation. Inset shows the dependence of the pseudo-first-order rate constant of ${ }^{3} 1^{*}$ decay (monitored at $560 \mathrm{~nm}$ ) on the triphenylamine concentration.

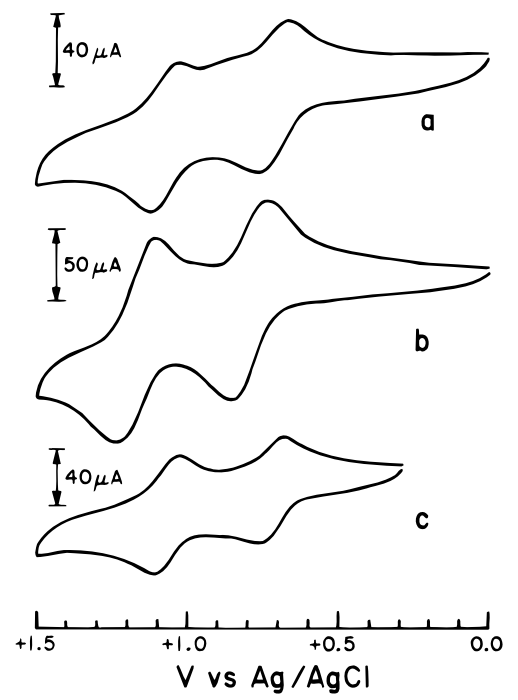

Figure 8. Cyclic voltammograms of squaraine dyes in methylene chloride containing $0.1 \mathrm{M}$ TBAP. The concentrations of the dyes were: (a) $1 \mathrm{mM}$ of $\mathbf{1}$, (b) $1.86 \mathrm{mM}$ of $\mathbf{2}$, and (c) $1 \mathrm{mM}$ of $\mathbf{3}$.

TABLE 3: Redox Potentials of Squaraine Dyes ${ }^{a}$

\begin{tabular}{ccc}
\hline dye & $E_{1}(\mathrm{mV})$ & $E_{2}(\mathrm{mV})$ \\
\hline $\mathbf{1}$ & 713 & 1072 \\
$\mathbf{2}$ & 792 & 1168 \\
$\mathbf{3}$ & 715 & 1062
\end{tabular}

${ }^{a}$ In methylene chloride with SCE as a reference electrode.

as determined from the slope of these plots are summarized in Table 1 . Nearly diffusion-controlled rate constants ${ }^{30}$ observed for the $\mathrm{T}-\mathrm{T}$ energy transfer in these experiments suggested that the triplet energies of the three dyes are significantly lower than the triplet energies of the two sensitizers.

Time resolved transient absorption spectra recorded during the formation of ${ }^{3} 1^{*}$ in chloroform (with triplet excited $\mathrm{C}_{60}$ as sensitizer) and ${ }^{3} 2 *$ in acetonitrile (with triplet excited 1-pyrenecarboxaldehyde as sensitizer) are shown in Figure 3A,B, respectively. The spectra recorded immediately after the laser flash correspond to the sensitizer triplets $\left(\lambda_{\max }=740 \mathrm{~nm}\right.$ for ${ }^{3} \mathrm{C}_{60} * 31,32$ and $\lambda_{\max }=440 \mathrm{~nm}$ for $\left.{ }^{3}(1 \text {-pyrenecarboxaldehyde })^{*}\right)^{27}$. These sensitizer triplets decay as the acceptor triplet evolves with a maximum in the $540-560 \mathrm{~nm}$ region (reaction 3 ). The bleaching around $630 \mathrm{~nm}$ further confirms the depletion of ground state dye molecules to form excited squaraine dye triplets. The isosbestic point observed in the 590-600 nm region indicates that only two species $\left({ }^{3}(\text { dye })^{*}\right.$ absorption and 


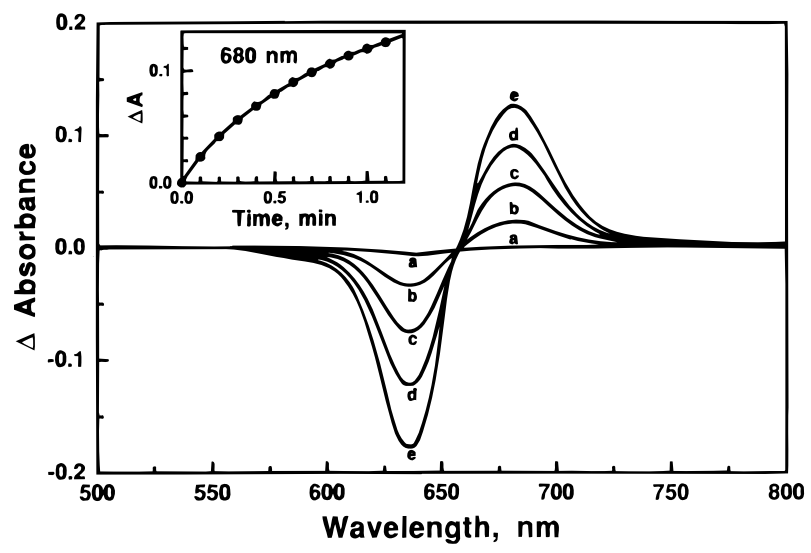

Figure 9. Difference absorbance spectra obtained by applying a potential of $0.8 \mathrm{~V}$ vs $\mathrm{Ag} / \mathrm{AgCl}$ in a methylene chloride solution containing $50 \mu \mathrm{M} 2$ and $0.1 \mathrm{M}$ TBAP. Inset shows the increase in absorbance at $680 \mathrm{~nm}$ with time.

dye depletion) contribute to the difference absorption spectra in Figure 3A,B.

The inset in Figure 3A shows the decay of ${ }^{3} \mathrm{C}_{60} *$ at $740 \mathrm{~nm}$ and the growth of ${ }^{3} \mathbf{1}^{*}$ at $560 \mathrm{~nm}$, while the inset in Figure 3B shows the decay of ${ }^{3}$ (1-pyrenecarboxaldehyde)* at $440 \mathrm{~nm}$ and a growth of ${ }^{3} 2 *$ at $560 \mathrm{~nm}$. The extinction coefficient of ${ }^{3} 1 *$ at the absorption maximum was determined by recording the maximum absorbance values of ${ }^{3}($ Sens $) *$ and ${ }^{3} 1 *$ and from eq 4

$$
\begin{aligned}
& \epsilon_{\max }\left({ }^{3} 1^{*}\right)= \\
& \epsilon_{\max }\left({ }^{3}(\text { Sens })^{*}\right) \Delta A_{\max }(540 \mathrm{~nm}) / \Delta A_{\max }(\text { Sens }) \times\left(1 / P_{\mathrm{et}}\right)
\end{aligned}
$$

where $\mathrm{P}_{\mathrm{et}}$ is the probability of energy transfer. ${ }^{27}$

Similarly, extinction coefficients of ${ }^{3} \mathbf{2}^{*}$ and ${ }^{3} \mathbf{3}^{*}$ were also determined (Table 1). These values were then employed to normalize the difference absorption spectra recorded in nanosecond laser flash photolysis experiments. The corrected absorption spectra of the triplet excited states of all three squaraine dyes were obtained by adding the ground-state absorption spectrum $\left(\mathrm{S}_{0}-\mathrm{S}_{1}\right)$ to the difference absorption spectrum, and these are shown in Figures $4 \mathrm{~A}-\mathrm{C}$, respectively. The spectral characteristics and lifetimes of the dye triplets are summarized in Table 1.

All these dye triplets have strong absorption in the visible region with difference extinction coefficients ranging from 71000 to $98000 \mathrm{M}^{-1} \mathrm{~cm}^{-1}$ in acetonitrile and from 49000 to $64000 \mathrm{M}^{-1} \mathrm{~cm}^{-1}$ in $\mathrm{CHCl}_{3}$. The variation in the difference extinction coefficients is likely due to the medium effects as well as uncertainty in the extinction coefficient values assumed for the sensitizer triplet. These dye triplets are relatively longlived (32-94 $\mu \mathrm{s})$ with lifetimes depending upon the medium, type of sensitizer, and the dye concentration.

Self-Quenching of Triplet Excited State. The triplet lifetimes of the three dyes were found to be dependent upon ground state dye concentration. As observed in previous studies, such a dependence is indicative of the self-quenching process (reactions 5 and 6).

$$
\begin{gathered}
{ }^{3}(\text { Dye })^{*}+\text { dye }\left(S_{0}\right) \rightarrow 2 \text { dye }\left(S_{0}\right) \\
{ }^{3}(\text { dye })^{*}+\text { dye }\left(S_{0}\right) \rightarrow \text { dye }^{\bullet+}+\text { dye }
\end{gathered}
$$

The bimolecular quenching rate constant for the quenching of ${ }^{3}$ (dye)* by the ground state dye molecule was determined by measuring the pseudo-first-order decay rate constants of ${ }^{3}(\text { dye })^{*}$ at various concentrations of squaraine dye in the $\mathrm{T}-\mathrm{T}$
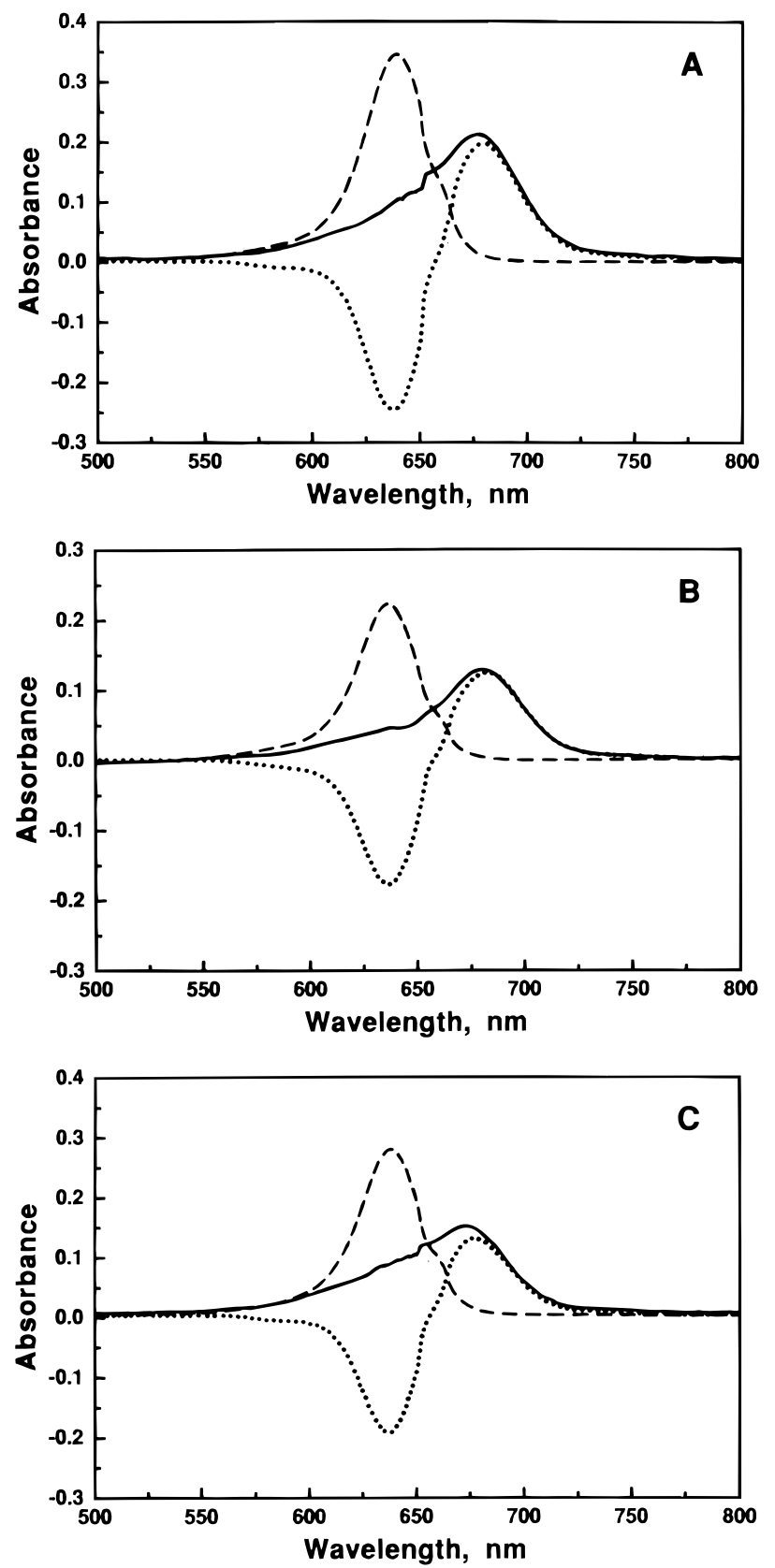

Figure 10. Comparison of the absorption spectra of cation radicals with those of ground state dyes, (A) 1, (B) 2, and (C) $\mathbf{3}$ in methylene chloride. The dotted line shows the difference absorbance spectra of dye cation obtained by applying a potential of $0.8 \mathrm{~V} \mathrm{vs} \mathrm{Ag} / \mathrm{AgCl}$ for $1.1 \mathrm{~min}$, the dashed line corresponds to the absorption spectra of ground state dye (normalized), and the solid line is the corrected absorbance spectra of dye cation obtained from the previous two spectra.

sensitization experiments. The concentration of ground state dye was maintained higher than ${ }^{3}$ (dye)* so that the change in dye concentration during the triplet decay was negligible. The linear dependence of the pseudo-first-order decay rate constant of ${ }^{3}$ (dye)* on the ground state dye concentration is shown in Figure 5. Bimolecular self-quenching rate constants for the three dyes in acetonitrile and chloroform which ranged between 0.5 $\times 10^{9}$ and $1.9 \times 10^{9} \mathrm{M}^{-1} \mathrm{~s}^{-1}$ (see Table 2) suggested a nearly diffusion-controlled quenching process of the triplet excited state. $^{30}$

It has been shown earlier that the quenching of the excited triplet by ground state dye molecules can lead to net electron transfer. Up to $50 \%$ electron transfer yield has been observed for thiazine dyes. ${ }^{33,34}$ In order to probe this feasibility (reaction 6) in the present case, time resolved transient absorption measurements were performed. The spectrum recorded at 
longer times, i.e., after the decay of triplet excited state, is attributed to the products formed during ground state quenching process (Figure 6A,B). Two different triplet sensitizers were employed to generate ${ }^{3} 1^{*}$ in these experiments.

The decay of ${ }^{3} \mathbf{1}^{*}$ at $560 \mathrm{~nm}$ in Figure 6A,B is accompanied by the formation of a peak at $680 \mathrm{~nm}$. Formation of new species is evident from the absorption-time profiles shown in the insets of this figure. (The initial decay of absorption in the inset of Figure $6 \mathrm{~A}$ is due to the decay of sensitizer triplet, ${ }^{3} \mathrm{C}_{60}{ }^{*}$.) The decay rate of the triplet dye matched well with the rate of formation of the transient at $680 \mathrm{~nm}$. Since the long-term spectra are similar in both of these examples (Figure 6A,B), we rule out any direct interaction between the ${ }^{3}(\text { dye })^{*}$ and sensitizer molecules in the ground state.

The spectral features of the transients observed in the ground state quenching process $(680 \mathrm{~nm}$ band in Figure 6A,B) match the spectral characteristics of the transient observed in the photoionization experiments (Figure 1). This indicates formation of cation and anion radicals of the dye in the ground state quenching process.

Photochemical Reduction with Triphenylamine. In order to characterize the radical anion of the squaraine dye, dye ${ }^{\bullet-}$, we carried out photochemical reduction with an electron donor. Aromatic amines such as triphenylamine (TPA) are known to interact with triplet excited dyes and participate in the electron transfer process.

$$
(\text { dye })^{*}+\mathrm{TPA} \rightarrow \mathrm{dye}^{\bullet-}+\mathrm{TPA}^{\bullet+}
$$

The bimolecular rate constant for reaction 7 as determined from the dependence of pseudo-first-order decay of ${ }^{3} \mathbf{1}^{*}$ on the TPA concentration (inset of Figure 7) was $1.4 \times 10^{7} \mathrm{M}^{-1} \mathrm{~s}^{-1}$. This rate constant for the reaction between ${ }^{3} \mathbf{1}^{*}$ and TPA is significantly lower than the rate constant for a diffusion controlled process.

Since $\mathrm{TPA}^{\bullet+}$ further undergoes chemical changes, ${ }^{35}$ the backelectron transfer between the two electron transfer products is retarded. This facilitates characterization of the radical anion of the squaraine dye. Figure 7 shows the time resolved transient absorption spectra recorded following the excitation of an aqueous solution containing 1-pyrenecarboxaldehyde $\mathbf{1}$ and TPA. It shows three major events following $337 \mathrm{~nm}$ laser pulse excitation: (a) formation of triplet excited sensitizer, ${ }^{3}$ (1-pyrenecarboxaldehyde)*, as indicated by the absorption at $440 \mathrm{~nm}$ (spectrum a), (b) formation and decay of ${ }^{3} \mathbf{1}^{*}$ as evident from the absorption band at $560 \mathrm{~nm}$ and bleaching at $640 \mathrm{~nm}$ (spectra $a$ and $b$ ), and (c) formation of radical anion with a transient absorption maximum at $670 \mathrm{~nm}$ (spectrum c).

The production of the transient absorption at $670 \mathrm{~nm}$ was dependent on the TPA concentration. With increasing quencher (TPA) concentration from 0 to $0.71 \mathrm{mM}, \Delta A_{\max }$ at $670 \mathrm{~nm}$ increased from 0.018 to 0.043 . This increase in absorbance also matched the bleaching of the ground state dye which further provided evidence for the conversion of excited dye into its reduced form. It is also noteworthy that the absorption band of anion radical coincides with the absorption of the cation radical (see below).

One Electron Oxidation. In order to characterize the radical cation of these dyes we employed both spectroelectrochemical and pulse radiolysis methods. The stability of radical cation in methylene chloride was especially useful in using these complementary techniques for obtaining information on the one electron oxidation product.

(a) Spectroelectrochemical Method. The electrochemical oxidation of several symmetrical squaraine dyes has been investigated earlier by Law and co-workers. ${ }^{36}$ Most of these dyes exhibit two reversible oxidations, and their oxidation

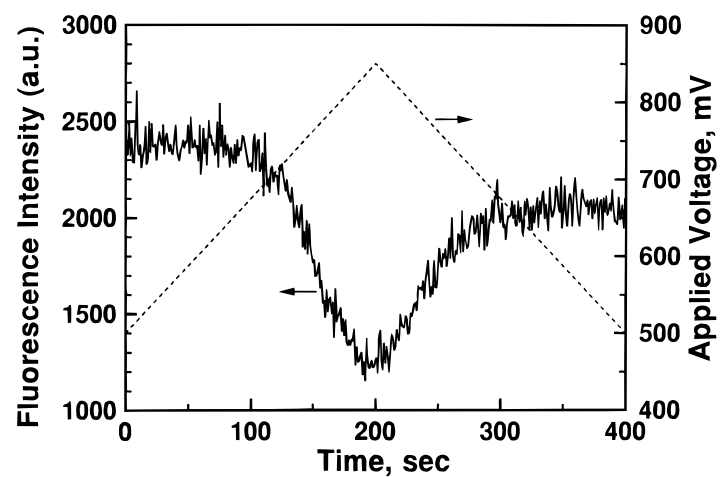

Figure 11. Dependence of the fluorescence intensity of $50 \mu \mathrm{M} 2$ in methylene chloride containing $0.1 \mathrm{M}$ TBAP on the applied potential (vs $\mathrm{Ag} / \mathrm{AgCl}$ ). The potential (shown on the right axis) was scanned at a rate of $2 \mathrm{mV} / \mathrm{s}$ (excitation wavelength $=600 \mathrm{~nm}$, and emission wavelength $=655 \mathrm{~nm}$ ).

potentials are influenced by substituent groups. It has been shown that these oxidation potentials are susceptible to the presence of alkali metal ions such as $\mathrm{Li}^{+}, \mathrm{Na}^{+}$, and $\mathrm{K}^{+}$as they complex with the crown ether moiety. ${ }^{17 a}$ The shift in the oxidation potential of $\mathbf{1}$ was dependent on the concentration of metal ions. This property is quite useful in quantitative determination of metal ions. We have now utilized spectroelectrochemical measurements in a thin layer cell to characterize the radical cation of squaraine dyes.

Dyes 1-3 exhibit two reversible oxidations in methylene chloride. The cyclic voltammograms of these three dyes are shown in Figure 8, and the oxidation potentials are summarized in Table 3. The two oxidations are distinct with the first oxidation occurring in the $0.71-0.79 \mathrm{~V}$ vs SCE potential range and the second oxidation occurring in the $1.06-1.17 \mathrm{~V}$ vs SCE potential range. Both of these potentials are significantly greater than the oxidation potential of several substituted bis(4(dimethylamino)phenyl)squaraine dyes reported earlier. ${ }^{36}$ This may be the result of decreasing charge transfer character caused by the crown ether moiety. Donor-acceptor molecules usually show a decrease in oxidation potential as the charge transfer character increases. ${ }^{37}$

Spectroelectrochemical experiments were carried out in a thin layer cell consisting of an optically transparent electrode (working electrode), Pt counter electrode, and $\mathrm{Ag} / \mathrm{AgCl}$ reference electrode. The detail of the cell assembly is described elsewhere. ${ }^{25}$ The cell assembly was inserted into the sample chamber of the spectrophotometer so that absorption spectra could be recorded at any given applied electrochemical potential. The absorption spectra recorded at an applied potential of 0.8 $\mathrm{V}$ are shown in Figure 9. The applied potential of $+0.8 \mathrm{~V}$ ensured selective one electron oxidation of the squaraine dye. The difference absorption spectrum exhibits a strong absorption band in the red region with a maximum at $680 \mathrm{~nm}$ and a bleaching at $640 \mathrm{~nm}$. Both of these bands increased with time as more of the dye gets oxidized at the electrode surface. Similar absorption bands were also observed for dyes $\mathbf{1}$ and $\mathbf{3}$. The isosbestic point observed around $660 \mathrm{~nm}$ confirmed stoichiometric conversion of the dye into its cation radical.

Figure 10 shows the difference absorption spectra and corrected spectra of the cation radicals of all three dyes. The ground state spectrum of the corresponding dye is also shown for comparison. The absorption features of these radical cations were very similar with a difference absorption maximum around $680 \mathrm{~nm}$. This absorption feature is similar to the difference absorption spectrum of radical cations produced in the laser flash photolysis experiment.

An effort was also made to probe the one electron oxidation by fluorometry. As discussed in our previous study, ${ }^{17 \mathrm{~b}}$ these 

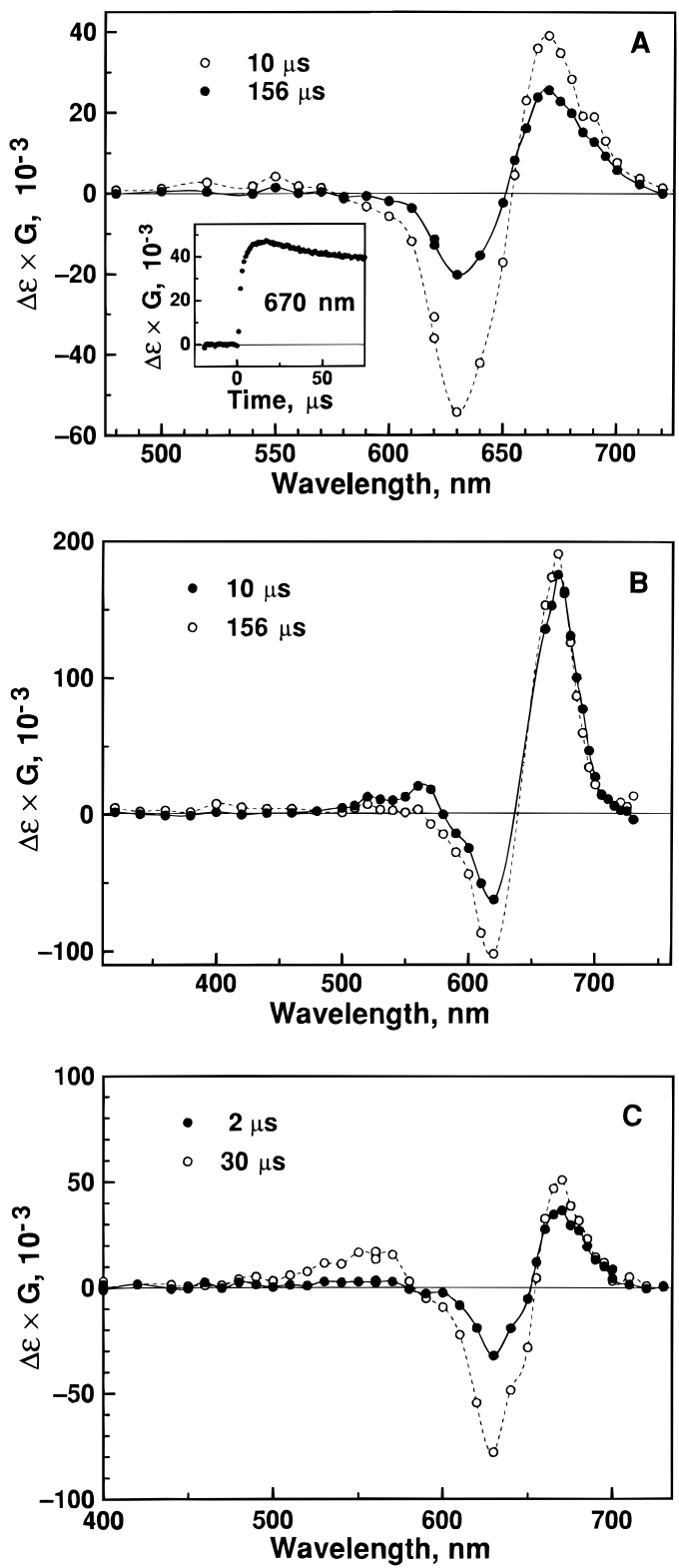

Figure 12. The transient absorption spectra of radical cations of (A) 1, (B) 2, (C) 3 in methylene chloride saturated with oxygen. The concentration of the dye was in the range of $5-10 \mu \mathrm{M}$. The spectra were recorded at (a) $2 \mu \mathrm{s}$ and (b) $78 \mu \mathrm{s}$ after pulse radiolysis. The inset of A shows an example ofthe absorption-time profile at $670 \mathrm{~nm}$.

squaraine dyes are highly fluorescent with emission maximum around $660 \mathrm{~nm}$. The spectroelectrochemical cell described above was introduced into the sample chamber of the fluorometer. The fluorescence intensity was continuously monitored while scanning the electrochemical potential in the range of $500-850 \mathrm{mV}$. The fluorescence intensity decreased as the applied potential was increased from 0.5 to $0.85 \mathrm{~V}$ (Figure 11). Upon reversal of the potential, most of the fluorescence intensity was restored. These experiments indicate that the radical cation is nonfluorescent and that the changes in fluorescence intensity can be conveniently utilized to probe the one electron oxidation process of these dyes.

(b) Pulse Radiolysis. Pulse radiolysis of organic solvents provides a convenient way to generate radical intermediates in a controlled way. For example, radiolysis of methylene chloride yields reactive radical species such as $\mathrm{RCl}^{\bullet} .^{38-42}$

$$
\begin{aligned}
& \mathrm{CH}_{2} \mathrm{Cl}_{2} m \rightarrow\left[\left(\mathrm{CH}_{2} \mathrm{Cl}_{2}^{+}\right)^{*}, \mathrm{e}^{-}\right] \rightarrow \\
& \mathrm{CHCl}^{+}, \mathrm{CH}_{2} \mathrm{Cl}^{+},{ }^{\cdot} \mathrm{CH}_{2} \mathrm{Cl},{ }^{\bullet} \mathrm{Cl}, \mathrm{Cl}^{-}
\end{aligned}
$$

In oxygenated solutions, ${ }^{\circ} \mathrm{CH}_{2} \mathrm{Cl}$ reacts with $\mathrm{O}_{2}$ to generate $\mathrm{CH}_{2} \mathrm{ClOO}^{\circ}$, which also acts as an oxidative species. The reaction between 1 and $\mathrm{CH}_{2} \mathrm{ClOO}^{\circ}$ is expected to yield the radical cation of the dye.

The transient absorption spectrum recorded, following the pulse radiolysis of methylene chloride solution containing $\mathbf{1}$, is shown in Figure 12A. The absorption maximum at $670 \mathrm{~nm}$ and the bleaching at $640 \mathrm{~nm}$ seen in the difference absorption spectrum provide further evidence for the spectral characterization of the radical cation of the dye. Cation radicals of dyes 2 and $\mathbf{3}$ also exhibited similar spectral characteristics when generated pulse radiolytically (Figure 12B,C). Thus, both spectroelectrochemical and pulse radiolysis experiments provide useful information for characterizing the transients generated in a photochemical reaction. A better understanding of the behavior of such transient intermediates is useful for designing improved photosensitizing systems for light energy conversion and imaging science application.

\section{Conclusion}

Direct laser photolysis of crown ether derivatives of squaraine dyes results in the production of different transient intermediates such as excited triplets, radical anions, and radical cations. Similarly, the ground state dye molecules are capable of quenching the excited triplet state with a nearly diffusion controlled rate and generate radical cations and radical anions in detectable yields. By selectively controlling the experimental conditions, it has been possible to characterize these individual transient species. Stable radical cations of these dyes can also be generated by electrochemical and radiolytic methods. The triplet excited state, radical anion, and radical cation of all three dyes exhibit strong absorption in the visible. The type of crown ether moiety had little effect on the spectral features of these dyes but influenced their oxidation potentials. Although substituent groups on the phenyl ring are capable of influencing the intramolecular charge transfer in the excited state, the size of the crown ether moiety seems to have no major effect.

Acknowledgment. G.S., P.V.K., and M.V.G. thank the Office of Basic Energy Sciences of the U. S. Department of Energy and (K.G.T., K.J.T., S.D., and M.V.G.) the Council of Scientific and Industrial Research, Government of India, for financial support of this work. This is Contribution No. RRLTPRU-63 from the Regional Research Laboratory, Trivandrum, and NDRL No. 3854 from the Notre Dame Radiation Laboratory.

\section{References and Notes}

(1) Bigelow, R. W.; Freund, H. J. Chem. Phys. 1986, 107, 159.

(2) Law, K. Y. Chem. Rev. 1993, 93, 449.

(3) Kamat, P. V.; Das, S.; Thomas, K. G.; George, M. V. J. Phys. Chem. 1992, 96, 195.

(4) Das, S.; Thomas, K. G.; Ramanathan, R.; George, M. V.; Kamat, P. V. J. Phys. Chem. 1993, 97, 13625.

(5) Law, K. Y. J. Phys. Chem. 1987, 91, 5184.

(6) Das, S.; Kamat, P. V.; De la Barre, B.; Thomas, K. G.; Ajayaghosh, A.; George, M. V. J. Phys. Chem. 1992, 96, 10327.

(7) Das, S.; Thomas, K. G.; George, M. V.; Kamat, P. V. J. Chem. Soc., Faraday Trans. 1992, 88, 3419.

(8) Law, K. Y. J. Imaging Sci. 1990, 34, 38.

(9) Scott, G. W.; Tran, K. J. Phys. Chem. 1994, 98, 11563.

(10) Liang, K.; Law, K. Y.; Whitten, D. G. J. Phys. Chem. 1994, 98, 13379

(11) Das, S.; Thomas, K. G.; Kamat, P. V.; George, M. V. Proc.-Indian Acad. Sci., Chem. Sci. 1993, 105, 513.

(12) Hotchandani, S.; Das, S.; Thomas, K. G.; George, M. V.; Kamat, P. V. Res. Chem. Intermed. 1994, 20, 927.

(13) Kamat, P. V.; Hotchandani, S.; deLind, M.; Thomas, K. G.; Das, S.; George, M. V. J. Chem. Soc., Faraday Trans. 1993, 89, 2397.

(14) Kim, Y.-S.; Liang, K.; Law, K.-Y.; Whitten, D. G. J. Phys. Chem. 1994, 98,984 
(15) Patrick, B.; George, M. V.; Kamat, P. V.; Das, S.; Thomas, K. G. J. Chem. Soc., Faraday Trans. 1992, 88, 671.

(16) Law, K. Y. Chem. Phys. Lett. 1992, 200, 121.

(17) (a) Das, S.; Thomas, K. G.; Thomas, J.; George, M. V.; Bedja, I.; Kamat, P. V. Anal. Proc. 1995, 32, 213. (b) Das, S.; Thomas, K. G.; Thomas, J.; George, M. V.; Kamat, P. V. J. Phys. Chem. 1994, 98, 9291.

(18) (a) Beer, P. D. Endeavour New Ser. 1992, 16, 182. (b) Beer, P

D.; Danks, J. P.; Hesek, D.; McAleer, J. F. J. Chem. Soc., Chem. Commun. 1993, 1735.

(19) Bissel, R. A.; de Silva, A. P.; Gunaratne, H. Q. N.; Lynch, P. L. M.; Maguire, G. E. M.; Sandanayake, K. R. A. S. Chem. Soc. Rev. 1992, $21,187$.

(20) Lehn, J.-M. Angew. Chem., Int. Ed. Engl. 1990, 29, 1304.

(21) Sutherland, I. O. In Crown compounds towards future applications; Cooper, S. R., Ed.; VCH: New York, 1992; pp 235.

(22) Letard, J. F.; Lapouyade, R.; Rettig, W. Pure Appl. Chem. 1993, 65,1705

(23) Martin, M. M.; Plaza, P.; Hung, N. D.; Meyer, Y. H.; Bourson, J.; Valeur, B. Chem. Phys. Lett. 1993, 203, 425.

(24) Nagarajan, V.; Fessenden, R. W. J. Phys. Chem. 1985, 89, 2330. (25) Bedja, I.; Hotchandani, S.; Kamat, P. V. J. Phys. Chem. 1993, 97, 11064.

(26) Janata, E.; Schuler, R. H. J. Phys. Chem. 1982, 86, 2012.

(27) Carmichael, I.; Hug, G. L. J. Phys. Chem. Ref. Data 1986, 15.

(28) Arbogast, J. W.; Darmanyan, A. P.; Foote, C. S.; Rubin, Y.;
Diederich, F. N.; Alvarez, M. M.; Anz, S. J.; Whetten, R. L. J. Phys. Chem. 1991, 95, 11.

(29) Zeng, Y.; Biczok, L.; Linschitz, H. J. Phys. Chem. 1992, 96, 5237.

(30) Saltiel, J.; Atwater, B. W. Adv. Photochem. 1988, 14, 1.

(31) Biczok, L.; Linschitz, H.; Walter, R. I. Chem. Phys. Lett. 1992, $195,339$.

(32) Dimitrijevic, N. M.; Kamat, P. V. J. Phys. Chem. 1992, 96, 4811.

(33) Kamat, P. V.; Lichtin, N. N. J. Phys. Chem. 1981, 85, 814.

(34) Kamat, P. V.; Lichtin, N. N. J. Photochem. 1982, 18, 197.

(35) Pienta, N. J. Amines, Thiols, and Thioethers: Heteroatomic Electron Donors. In Photoinduced Electron Transfer; Fox, M. A., Chanon, M., Eds.; Elsevier: New York, 1988; Vol. D; pp 421.

(36) Law, K.-Y.; Facci, J. S.; Balley, F. C.; Yanus, J. F. J. Imaging Sci. 1990, 34,31 .

(37) Loutfy, R. O.; Law, K.-Y. J. Phys. Chem. 1980, 84, 2803.

(38) Bobrowski, K.; Das, P. K. J. Phys. Chem. 1985, 89, 5079.

(39) Ford, W. E.; Hiratsuka, H.; Kamat, P. V. J. Phys. Chem. 1989, 93, 6692.

(40) Grodkowski, J.; Neta, P. J. Phys. Chem. 1984, 88, 1205.

(41) Wang, Y.; Tria, J. J.; Dorfman, L. M. J. Phys. Chem. 1979, 83, 1946.

(42) Yamamoto, Y.; Nishida, S.; Hayashi, K. J. Chem. Soc., Faraday Trans. 1 1987, 83, 1795.

JP9520815 